\title{
Analisis Termal-hidrolik Reaktor Air Bertekanan (Pressurized Water Reactor) Menggunakan Metode LU Faktorisasi
}

\author{
Dewi N.F.F.Efendi ${ }^{(1)^{*}}$, Yanti Yulianti ${ }^{(1)}$, dan Syafriadi ${ }^{(1)}$ \\ ${ }^{(1)}$ Jurusan Fisika FMIPA Universitas Lampung \\ Jl.Prof. Dr. Soemantri Brojonegoro No.1 Gedung Meneng Bandar Lampung 35145 \\ *E-mail:dewiefendiphysics@gmail.com
}

Diterima (25 April 2018), direvisi (16 Mei 2018)

\begin{abstract}
The Research about Pressurized Water Reactors (PWR) thermal-hydraulics analysis has been done. This reseacrh aim to solve fuel rod heat conduction equation by LU Factorization method and to get thermal-hydraulics parameters such as coolant axial temperature distribution, pressure drops, convection heat transfer coefficient, and fuel rod radial temperature distribution. Heat transfer of the reactors was assumted steady state (time independent) then obtained coolant inlet tempertaure about $300{ }^{\circ} \mathrm{C}$, outlet temperature about $326,6{ }^{\circ} \mathrm{C}$ and convection heat transfer coefficient $h_{s}$ about $1,43 \mathrm{~W} / \mathrm{cm}^{2}{ }^{\circ} \mathrm{C}$. Pressure drop by friction was 0,423 bar, pressure drop by form was 0,51 bar, pressure drop by gravity was 0,25 bar and total pressure drop was 1,183 bar. While centerline fuel obtained the maximum temperature of fuel rod about $1.589,2{ }^{\circ} \mathrm{C}$ and the lowest fuel rod temperature at cladding surface about $360,9953{ }^{\circ} \mathrm{C}$.
\end{abstract}

Keywords: Thermal-hydraulics, LU Decomposition, PWR, Matlab

\begin{abstract}
Abstrak.Penelitian tentang analisis termal-hidrolik reaktor air bertekanan (Pressurized Water Reactor) telah dilakukan. Penelitian ini bertujuan menyelesaikan persamaan konduksi panas untuk batang bahan menggunakan metode LU Faktorisasi dan memperoleh nilai parameter termal-hidrolik seperti distribusi temperatur aksial pendingin, penurunan tekanan, koefisien transfer panas dan distribusi temperatur radial bahan bakar. Dengan asumsi perpindahan panas reaktor pada kondisi tunak (tidak bergantung waktu) maka diperoleh temperatur pendingin inlet adalah $300{ }^{\circ} \mathrm{C}$, outlet adalah $326,6{ }^{\circ} \mathrm{C}$ serta koefisien transfer panas konveksi $h s$ sebesar $1,43 \mathrm{~W} / \mathrm{cm}^{2}{ }^{\circ} \mathrm{C}$. Penurunan tekanan akibat friksi diperoleh sebesar 0,423 bar, penurunan tekanan akibat bentuk (form) sebesar 0,51 bar, penurunan tekanan akibat gravitasi sebesar 0,25 bar dan penurunan tekanan total yaitu 1,183 bar. Sedangkan temperatur pada batang bahan bakar diperoleh nilai maksimum pada garis-tengah bahan bakar yaitu $1.589,2^{\circ} \mathrm{C}$ dan temperatur terendah batang bahan bakar pada permukaan kelongsong yaitu $360,9953{ }^{\circ} \mathrm{C}$.
\end{abstract}

Kata kunci: Termal-hidrolik, LU Faktorisasi, PWR, Matlab

\section{PENDAHULUAN}

Reaktor nuklir adalah pembangkit listrik yang memanfaatkan energi panas yang dihasilkan oleh reaksi fisi berantai dari bahan bakar nuklir. Reaktor yang paling banyak digunakan di dunia adalah reaktor air bertekanan atau yang sering disebut Pressurized Water Reactor(PWR) [1]. PWR merupakan jenis reaktor yang pendinginnya menggunakan air dengan dua sistem pendinginan. Reaktor ini termasuk dalam salah satu jenis reaktor air ringan (Light Water Reactors atau LWR) [2].

Aspek yang penting dalam analisis reaktor yaitu termal-hidrolik reaktor. Analisis termal-hidrolik tersebut meliputi distribusi temperatur aksial kanalpendingin, transfer panas (heat transfer), penurunan tekanan (pressure drop), dan ditribusi temperatur radial[3].Untuk mempermudah menyelesaikan perhitungan termal-hidrolik, pada penelitian ini digunakan sebuah 
metode numerik yaitu LU Faktorisasi dan sebuah software pemrograman Matlab.

Matlab atau MATrix LABoratory merupakan bahasa pemrograman tingkat tinggi yang digunakan untuk mempermudah dalam komputasi teknik, diantaranya seperti penyelesaian permasalahan matematis, visualisasi dari penyelesaian masalah, dan simulasi sains. Semakin tinggi tingkatan suatu bahasa pemrograman maka semakin mudah dalam penyelesaian permasalahannya[4].

Metode LU Faktorisasi merupakan metode penyelesaian persamaan linier dengan menggunakan faktorisasi dari matrik A menjadi matrik segitiga bawah $\mathbf{L}$ (lower) dan matrik segitiga atas $\mathbf{U}$ (upper). Faktorisasi ini dapat menggunakan teknik pivoting seperti pada penyelesaian dengan menggunakan metode Eliminasi Gauss. Tapi berbeda dengan Eliminasi Gauss, LU Faktorisasi menggunakan langkah yang dibuang pada Eliminasi Gauss. Pada Eliminiasi Gauss, faktor pengali pada saat pivoting tidak digunakan lagi untuk menyelesaikan persamaannya sedangkan pada LU Faktorisasi, faktor pengali tersebut digunakan kembali unutk membantuk matrik segitiga bawah $\mathbf{L}[5]$.

Isnaini melakukan analisis desain termal-hidrolik subkanal elemen bahan bakar untuk reaktor jenis PWR yang dikembangkan oleh Korea yaitu Korean Standard Nuclear Plant(PWR-KSNP). Pada penelitiannya digunakan konfigurasi matrik elemen bahan bakar $2 \times 2$ dengan program COBRA IV-I[6].Khoiri membuat kode komputer untuk menganalisis termalhidrolik subkanal untuk pendingin reaktor jenis Light Water Reactor (LWR) menggunakan program Borland Delphi 7 [7] .

\section{METODE PENELITIAN}

Penelitian ini menggunakan laptop dengan sistem operasi windows 10 dan program Matlab R2014a. Termal-hidrolik diawali dengan menghitung distribusi temperatur pendingin pada kanal pendingin, nilai koefisien transfer panas konveksi $h_{s}$, dan penurunan tekanan pendingin. Persamaan (1) digunakan untuk menghitung distibusi temperatur aksial pendingin $T_{f l}$.

$$
T_{f l}(z)=T_{\text {inlet }}+\frac{q^{\prime}{ }_{0}^{\widetilde{H}}}{\pi c_{p} w}\left[\sin \left(\frac{\pi z}{\widetilde{H}}\right)+\sin \left(\frac{\pi H}{\widetilde{2 H}}\right)\right]
$$

Dengan $T_{\text {inlet }}$ adalah temperatur pendingin yang masuk kanal, $q_{0}^{\prime}$ adalah rata-rata kerapatan daya linier $[\mathrm{W} / \mathrm{cm}], \widetilde{H}$ adalah panjang kanal ditambah dengan jarak ekstrapolasi $[\mathrm{cm}], c_{p}$ adalah kapasitas panas fluida $\left[\mathrm{W} / \mathrm{cm}^{\circ} \mathrm{C}\right], w$ adalah kecepatan aliran massa $[\mathrm{g} / \mathrm{cm}], z$ adalah posisi titik partisi, dan $H$ adalah panjang kanal [cm]. Koefisien transfer panas konveksi $h_{s}$ dan penurunan tekanan pendingin $\Delta p$ dihitung dengan menggunakan persamaan berikut.

$$
\begin{gathered}
h_{s}=\left(k / D_{h}\right) N u \\
\Delta p_{\text {friction }}=2\left(L / D_{h}\right) \rho \bar{u}_{z}^{2} f \\
\Delta p_{\text {form }}=\sum_{i} K_{i} \rho \frac{\bar{u}^{2}}{2} \\
\Delta p_{\text {gravitasi }}=\rho g H
\end{gathered}
$$

Dengan $k$ adalah konduktivitas panas fluida $\left[\mathrm{W} / \mathrm{cm}^{\circ} \mathrm{C}\right], D_{h}$ adalah diameter ekuivalen kanal [cm], dan $\mathrm{Nu}$ adalah bilangan Nusselt untuk menghitung $h_{s}$. Sedangkan untuk $\Delta p$ diperlukan yaitu $L$ sama dengan $H$ adalah panjang kanal $[\mathrm{cm}], \rho$ adalah densitas fluida $\left[\mathrm{gram} / \mathrm{cm}^{3}\right.$ ], $\bar{u}_{z}$ adalah ratarata laju aliran fluida $\left[\mathrm{gram} / \mathrm{cm}^{2} \mathrm{~s}^{2}\right], \quad f$ adalah faktor friksi fanning, $K_{i}$ adalah faktor friksi bentuk, dan $g$ adalah gravitasi. 


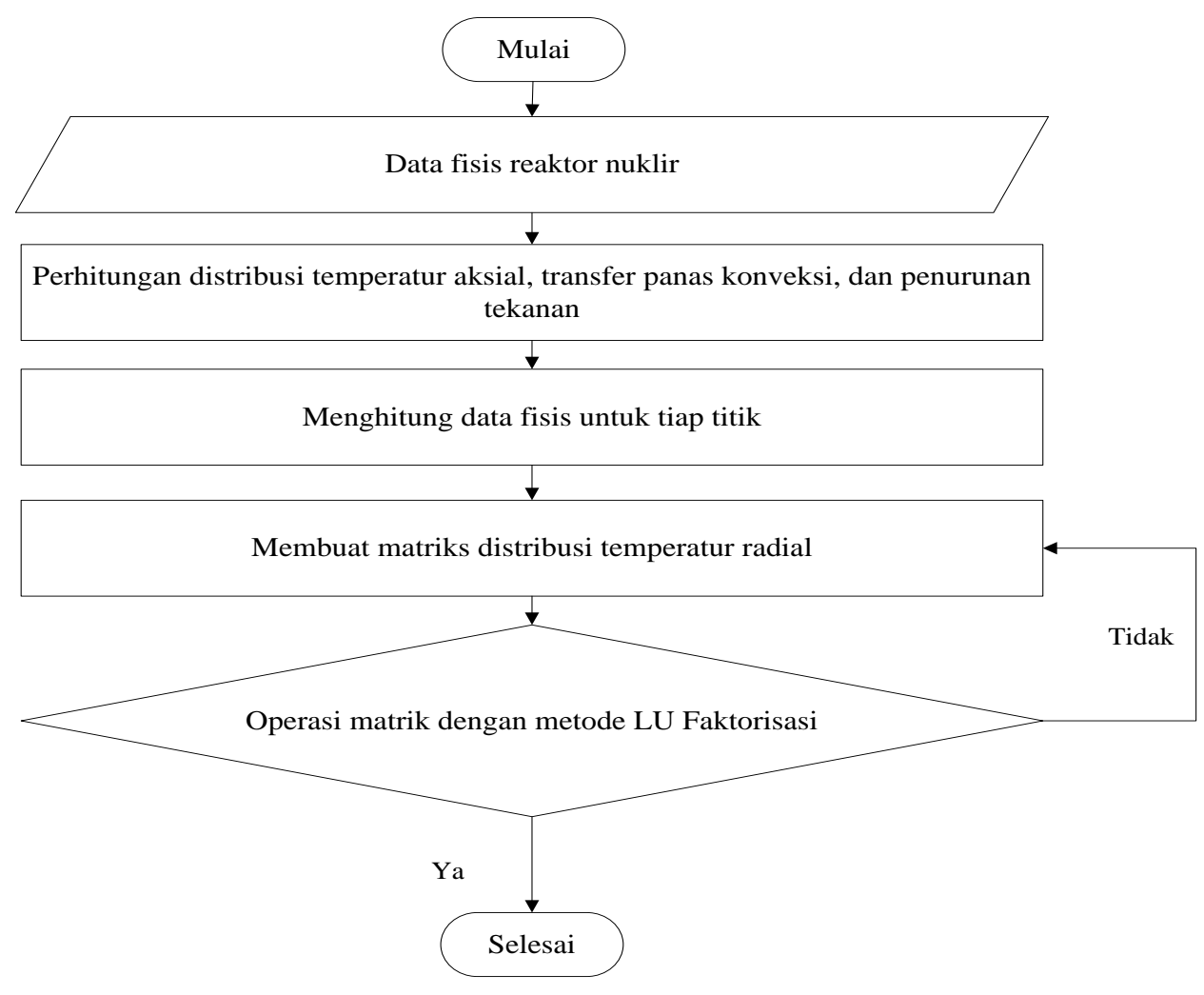

Gambar 1. Diagram alir penelitian

Kemudian dilakukan perhitungan distribusi temperatur radial bahan bakar menggunakan persamaan konduksi panas yang telah didiskritisasi dan diselesaikan dengan metode LU Faktorisasi, kemudian pembuatan program dengan menggunakan software Matlab. Selanjutnya menjalankan program dan diperoleh hasil berupa nilaitemperatur pendingin $h_{s}$, penurunan tekanan, dan bahan bakar radial. Selain itu, diperoleh pula grafik distribusi termperatur pendingin dan bahan bakar radial.

Persamaan konduksi panas diasumsikan pada kondisi tunak atau tidak bergantung waktu. Karena batang bahan bakar yang digunakan berbentuk silinder sehingga digunakan koordinat silinder satu dimensi yang mana perubahan temperatur hanya bergantung pada jarak $r$ yang ditunjukkan oleh persamaan (6)

$-\frac{1}{r} \frac{d}{d r} k r \frac{d T}{d r}=q^{\prime \prime \prime}$ karena pada gap dan kelongsong tidak terjadi produksi energi maka konduksi panas pada gap dan kelongsong digunakan persamaan (7).

$-\frac{1}{r} \frac{d}{d r} k r \frac{d T}{d r}=0$

\section{HASIL DAN PEMBAHASAN}

Untuk mengetahui distribusi temperatur radial pada bahan bakar, maka perlu menggunakan persamaan konduksi panas. Penyelesaian persamaan konduksi panas (6) dan (7) dengan metode LU Faktorisasi daitunjukkan oleh persamaan (8) dan (9)

$-k\left(\frac{T_{i-1}-2 T_{i}+T_{i+1}}{\Delta^{2}}-\frac{1}{r} \frac{T_{i+1}-T_{i-1}}{2 \Delta}\right)=q^{\prime \prime \prime}$

$-k\left(\frac{T_{i-1}-2 T_{i}+T_{i+1}}{\Delta^{2}}-\frac{1}{r} \frac{T_{i+1}-T_{i-1}}{2 \Delta}\right)=0$

persamaan (3) dan (4) menghasilkan pola yaitu: 


$$
\begin{aligned}
& a_{i, i-1} T_{i-1}+a_{i, i} T_{i}+a_{i, i+1} T_{i+1}=q^{\prime \prime \prime}(10) \quad a_{11} T_{1}+a_{12} T_{2}=q^{\prime \prime} \\
& a_{i, i-1} T_{i-1}+a_{i, i} T_{i}+a_{i, i+1} T_{i+1}=0 \\
& a_{21} T_{1}+a_{22} T_{2}+a_{23} T_{3}=q^{\prime \prime \prime} \\
& a_{32} T_{2}+a_{33} T_{3}+a_{34} T_{4}=\stackrel{(11)}{q}^{\prime \prime \prime} \\
& \text { dengan } \\
& a_{i, i}=\frac{2 k}{\Delta^{2}} \\
& a_{43} T_{3}+a_{44} T_{4}+a_{45} T_{4}=q^{\prime \prime \prime} \\
& a_{54} T_{4}+a_{55} T_{5}+a_{34} T_{4}=q^{\prime \prime \prime} \\
& a_{i, i+1}=-\frac{k}{\Delta^{2}}\left(1+\frac{1}{2 n}\right) \\
& a_{65} T_{5}+a_{66} T_{6}+a_{34} T_{4}=q^{\prime \prime \prime} \\
& a_{76} T_{6}+a_{77} T_{7}+a_{34} T_{4}=0 \\
& n \text { =banyaknya partisi yaitu } 9 \text {. } \\
& a_{87} T_{7}+a_{88} T_{8}+a_{34} T_{4}=0
\end{aligned}
$$
linier maka seperti persamaan berikut.

Kemudian persamaan tersebut akan menghasilkan matrik $\mathbf{A}$ dengan dimensi $n x n$ dan $\mathbf{b}$ dengan dimensi $1 x n$.

$$
\left.\left(\begin{array}{cccccc}
a_{11} & a_{12} & 0 & 0 & 0 & 0 \\
a_{21} & a_{22} & a_{23} & 0 & 0 & 0 \\
0 & a_{32} & a_{33} & a_{34} & 0 & 0 \\
0 & 0 & \ddots & \ddots & \ddots & 0 \\
0 & 0 & 0 & \ddots & \ddots & \ddots \\
0 & 0 & 0 & 0 & \ddots & \ddots
\end{array}\right) \quad\left(\begin{array}{c}
\mathbf{x} \\
T_{1} \\
T_{2} \\
T_{3} \\
T_{4} \\
\vdots \\
T_{n}
\end{array}\right) \quad=\quad \begin{array}{c}
\mathbf{b} \\
q^{\prime \prime \prime} \\
q^{\prime \prime \prime} \\
q^{\prime \prime \prime} \\
q^{\prime \prime \prime} \\
\vdots \\
0
\end{array}\right)
$$

Kemudian matrik A didekomposisi menjadi matrik diagonal atas $\mathbf{U}$ (upper) dan matrik diagonal bawah $\mathbf{L}$ (lower).

$$
\left(\begin{array}{cccccc}
U_{11} & U_{12} & 0 & 0 & 0 & 0 \\
0 & U_{22} & U_{23} & 0 & 0 & 0 \\
0 & 0 & U_{33} & U_{34} & 0 & 0 \\
0 & 0 & 0 & \ddots & \ddots & 0 \\
0 & 0 & 0 & 0 & \ddots & \ddots \\
0 & 0 & 0 & 0 & 0 & \ddots
\end{array}\right) \quad\left(\begin{array}{cccccc}
1 & 0 & 0 & 0 & 0 & 0 \\
L_{21} & 1 & 0 & 0 & 0 & 0 \\
0 & L_{32} & 1 & 0 & 0 & 0 \\
0 & 0 & L_{43} & 1 & 0 & 0 \\
0 & 0 & 0 & L_{54} & 1 & 0 \\
0 & 0 & 0 & 0 & \ddots & \ddots
\end{array}\right)
$$

Kemudian matrik $\mathbf{L}$ dan $\mathbf{b}$ dilakukan subtitusi maju sehingga menghasilkan matrik baru $\mathbf{y}(\mathbf{L} \mathbf{y}=\mathbf{b})$.

$$
\begin{gathered}
y_{1}=q^{\prime \prime \prime} \\
L_{21} y_{1}+y_{2}=q^{\prime \prime \prime} \\
L_{32} y_{2}+y_{3}=q^{\prime \prime \prime} \\
\vdots \\
a_{n, n-1} T_{n-1}+T_{n}=0
\end{gathered}
$$

Setelah itu dilakukan subtitusi mundur menggunakan matrik b dan $\mathbf{y}(\mathbf{U x}=\mathbf{y})$.

$$
\begin{gathered}
U_{n n} T_{n}=y_{n} \\
U_{n-1, n-1} T_{n-1}+U_{n-1, n} T_{n}=y_{n-1} \\
\vdots \\
U_{22} y_{2}+U_{23} T_{3}=y_{2} \\
U_{11} T_{1}+U_{12} T_{2}=y_{1}
\end{gathered}
$$


Distribusi Temparatur Aksial Pendingin

Perhitungan temperatur aksial
pendingin pada penelitian ini
mengasumsikan kanal tunggal dantidak
akan terjadi pendidihan di pendingin
primer. Oleh karenanya tidak akan terjadi
pergantian fase pendingin sehingga dalam
melakukan perhitungan digunakan asumsi
untuk aliran pendingin satu fase atau yang
sering disebut single-phase coolant [8].Nilai
rapat daya linier yang digunakan sebesar
178 W/cm, temperatur masukan air T
inletyaitu $300{ }^{\circ} \mathrm{C}$ dan panjang kanal yaitu
366 cm. Selain itu, teras reaktor diberi
tekanan sebesar 155 bar sehingga
temperatur saturasi pendingin pada tekanan
tersebut adalah $342,24{ }^{\circ} \mathrm{C}$. Oleh karena
pada PWR pendingin tidak boleh mendidih
maka temperatur pendingin tertinggi harus
berada di bawah temperatur saturasinya
[9].Kemudian diperoleh distribusi
temperatur seperti pada Gambar 2 .

Gambar 2 menunjukkan temperatur minimum pendingin berada pada bagian masuk (inlet) yaitu sebesar $300{ }^{\circ} \mathrm{C}$ dan temperatur tertinggi berada pada bagian atas (outlet) sebesar $326,26{ }^{\circ} \mathrm{C}$. Nilai ini masih dalam batas referensi nilai temperatur outlet pada reaktor PWR yang memiliki nilai outlet sampai dengan $332^{\circ} \mathrm{C}$ [3]. Selain itu, temperatur tertinggi pendingin ini berada di bawah temperatur saturasinya sehingga sesuai dengan sistem PWR. Pada gambar tersebut juga dapat dilihat grafik temperatur yang meningkat sepanjang kanal. Semakin ke atas maka temperatur pendingin pada kanal semakin meningkat [10]. Hal ini karena pendingin primer dari luar teras yang telah mengalami tranfer panas pada pendingin sekunder masuk melalui bawah[11].

\section{Transfer Panas Konveksi Paksa}

Karakterikstik pertama yang perlu dihitung pada penelitian ini untuk mengetahui nilai koefisien transfer panas $h_{s}$ adalah bilangan Nusselt $N u$, yaitu bilangan yang menunjukkan karakteristik sifat fisis pendingin dan dinamika alirannya. Bilangan $\mathrm{Nu}$ memerlukan dua bilangan yaitu bilangan Reynold Reyang menunjukkan dinamika aliran pendingin dan bilangan Pradtl Pryang menunjukkan karakteristik sifat fisis pendingin. Aliran pendingin memiliki dua karakteristik yaitu aliran laminar yang memiliki nilai $R e<2.100$ dan turbulen yang memiliki nilai $2.100<\operatorname{Re}<10^{5}[3]$.



Gambar 2. Distribusi temperatur terhadap jarak aksial kanal pendingin. 


$$
\begin{gathered}
\operatorname{Re}=\rho \bar{u}_{z} D_{h} / \mu \\
\operatorname{Pr}=\mu c_{p} / k \\
N u=0,0155 \operatorname{Pr}^{0,6} R e^{0,83} \\
q^{\prime \prime}=h_{s}\left(T_{s}-T_{f l}\right)
\end{gathered}
$$

Dengan $\mu$ adalah viskositas fluida [gram $/ \mathrm{cm}$ $\mathrm{s}^{2}$ ] dan nilai diameter ekuivalen yaitu $1,1458 \mathrm{~cm}$, diperoleh nilai $R e$ sebesar 32.083,726. Nilai tersebut menunjukkan bahwa aliran pendingin merupakan turbulen [12].

Selanjutnya, menentukan nilai $\mathrm{Pr}$ menggunakan persamaan (32) dan diperoleh nilai $\operatorname{Pr}$ sebesar 6,974. Dengan nilai $\mathrm{Pr}$ tersebut, kemudian $\mathrm{Nu}$ diperoleh dengan menggunakan persamaan (33) dan diperoleh nilai $N u$ yaitu 273,2985. Koefisien transfer panas konveksi ditung menggunakan persamaan (2) dan diperoleh nilai sebesar $1,43 \mathrm{~W} / \mathrm{cm}^{20} \mathrm{C}$. Nilai dari koefisien transfer panas konveksi ini berada dalam rentang $h_{s}$ yaitu $0,5-4,5 \mathrm{~W} / \mathrm{cm}^{2 \circ} \mathrm{C}$ [3].

Temperatur permukaan kelongsong yang langsung terhubung dengan pendingin dapat dihitung menggunakan persamaan (34). Transfer panas dari pendingin ke permukaan kelongsong dengan koefisien difusi pendingin sebesar $1,43 \mathrm{~W} / \mathrm{cm}^{2 \circ} \mathrm{C}$, rata-rata fluks panas $68,5 \mathrm{~W} / \mathrm{cm}^{2}$, dan temperatur pendingin pada panjang aksial $183 \mathrm{~cm}$ yaitu $313,8870^{\circ} \mathrm{C}$ menghasilkan temperatur permukaan kelongsong $T_{S}$ sebesar $360,9953{ }^{\circ} \mathrm{C}$.

\section{Penurunan Tekanan aksial pendingin}

Penurunan tekanan pendingin dapat disebabkan oleh beberapa faktor yaitu akibat dari friksi dinding kelongsong, bentuk dari grid penjarak dan gravitasi [8]. Pertama adalah penurunan tekanan friksi, yaitu penurunan tekanan yang dipengaruhi permukaan dinding kelongsong yang ditunjukkan oleh sebuah faktor $f$ disebut juga faktor gesekan Fanning. Dengan bilangan Reynold $R e$ yaitu $32.083,726$, nilai $f$ dapat diperoleh dengan menggunakan persamaan (35)

$$
f=0.0791 R e^{-0,25}
$$

Sehingga diperoleh nilai $f$ yaitu 0.0059 . Setelah mendapatkan nilai $f$, nilai penurunan tekanan friksi pun diperoleh dengan menggunakan persamaan (3).

Nilai penurunan tekanan yang diperoleh adalah sebesar 0,423 bar. Selanjutnya penurunan tekanan pendingin akibat dari bentuk grid penjarak, masuk kanal dan keluar kanal. Grid penjarak merupakan suatu perangkat bantuan untuk menjaga batang bahan bakar tetap berada pada posisinya selain itu juga pendingin yang mengalir melewati ini akan mengalami perputaran sehingga dapat membantu dalam menghilangkan panas dari pendingin. Namun selain itu, grid penjarak dapat menjadi hambatan untuk pendingin dapat mengalir sehingga terjadi penurunan terkanan pendingin [13]. Sama seperti sebelumnya, penurunan tekanan ini dipengaruhi oleh sebuah faktor yaitu $K$. Nilai ini berbeda untuk setiap bentuknya dan pada penelitian ini digunakan nilai $K$ yaitu 1,25(Seung\& Gyoo, 2001),0,78 dan 1[8]yang mana masing-masing adalah nilai untuk grid penjarak, bentuk masuk kanal dan keluar kanal.

Dengan menggunakan persamaan (4) diperoleh nilai penurunan tekanan bentuk sebesar 0,51 bar. Kemudian penurunan tekanan yang dipengaruhi oleh gravitasi akibat dari aliran pendingin yang menuju ke atas yang kemudian dituliskan dalam persamaan (5). Dengan nilai kerapatan pendingin sebesar $0,7 \mathrm{gram} / \mathrm{cm}^{3}$, gravitasi sebesar $980 \mathrm{~cm} / \mathrm{s}^{2}$ dan $H$ yaitu $366 \mathrm{~cm}$, diperoleh nilai penurunan tekanan akibat gravitasi sebesar 0,25 bar. 


\section{Distribusi Temperatur Radial Pada Batang Bahan Bakar}

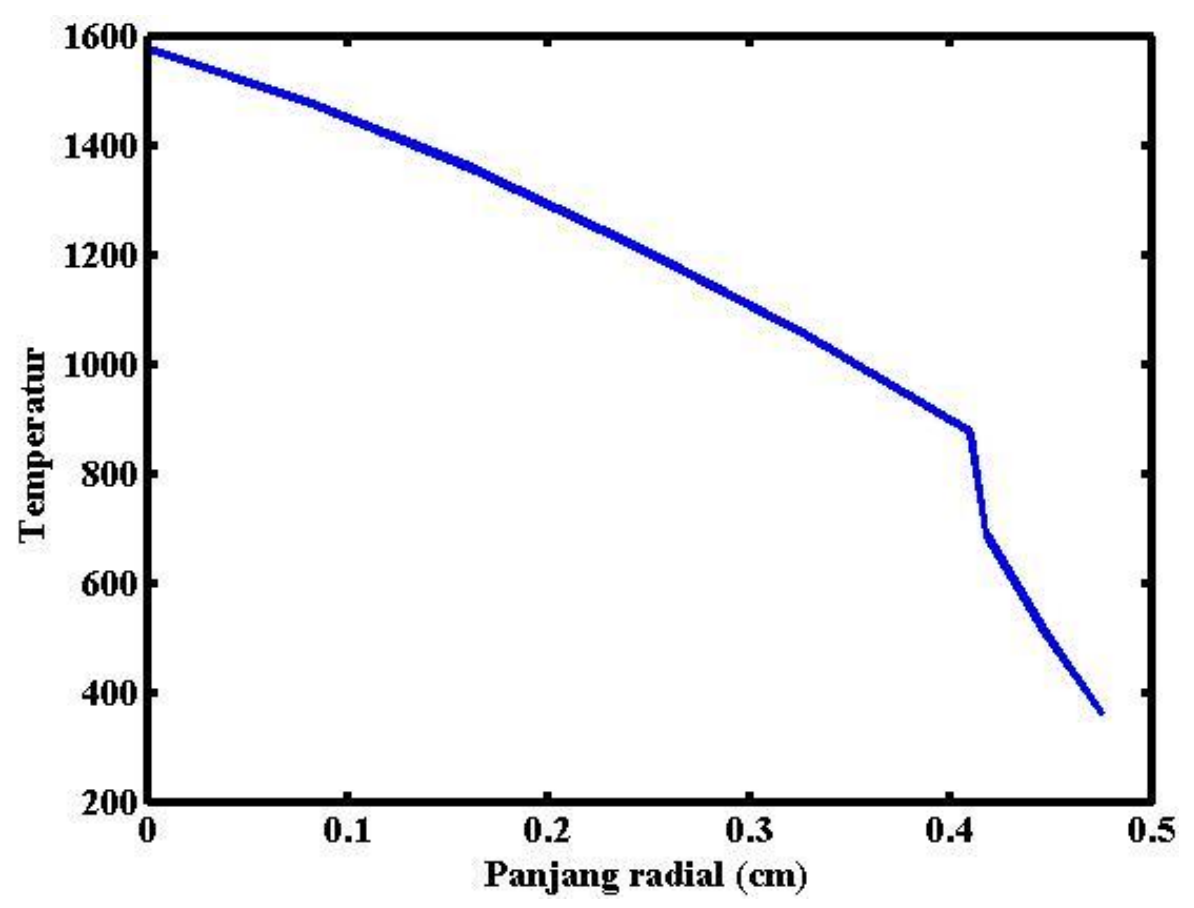

Gambar 3. Distribusi temperatur terhadap jarak radial pada batang bahan bakar

Gambar 3 menunjukkan nilai distribusi temperatur radial yang semakin menurun seiring dengan bertambahnya jarak yaitu maksimum temperatur garistengah bahan bakar adalah $1.589,2{ }^{\circ} \mathrm{C}$, dan temperatur pada permukaan kelongsong adalah $360,9953{ }^{\circ} \mathrm{C}$. Hal ini disebabkan karena energi panas hanya dihasilkan oleh reaksi fisi pada bahan bakar sedangkan pada gap dan kelongsong tidak diproduksi energi hanya mendapat hantaran panas secara konduksi dari bahan bakar. Berdasarkan analisis keselamatan bahwa bahan bakar reaktor memiliki temperatur maksimum yaitu $1.787,1^{\circ} \mathrm{C}$. Pertimbangan ini karena PWR memiliki titik leleh bahan bakar sebesar $2.800{ }^{\circ} \mathrm{C}$ untuk bahan bakar $\mathrm{UO}_{2}$. Temperatur garis-tengah bahan bakar sebesar 1.589,2 ${ }^{\circ} \mathrm{C}$ masih dibawah temperatur maksimum sehingga reaktor masih dalam kondisi aman dalam pengoperasiannya.

\section{KESIMPULAN}

Berdasarkan hasil yang diperoleh dapat disimpulkan bahwa persamaan distribusi temperatur terhadap panjang radial dapat diselesaikan menggunakan LU Faktorisasi dan diperoleh distribusi temperatur terhadap jarak yaitu $1.589,2{ }^{\circ} \mathrm{C}$ untuk temperatur maksimum pada garis-tengah batang bahan bakar dan $360,9953{ }^{\circ} \mathrm{C}$ untuk temperatur permukaan kelongsong. Perhitungan termal-hidrolik menghasilkan nilai koefisien difusi pendingin $h_{s}$ sebesar $1,43 \mathrm{~W} / \mathrm{cm}^{2 \circ} \mathrm{C}$, nilai penurunan tekanan friksi, bentuk dan gravitasi masing-masing sebesar 0,423 bar, 0,51 bar, dan 0,25 bar, serta distribusi temperatur aksial pendingin terhadap panjang kanal yaitu temperatur inlet sebesar $300{ }^{\circ} \mathrm{C}$ dan outlet sebesar $326,26^{\circ} \mathrm{C}$. 


\section{DAFTAR PUSTAKA}

[1] M. Djokolelono, "PWR SEBAGAI JENIS PLTN PALING LAKU SAAT INI," in TEKNOLOGI PUSAT LISTRIK TRNAGA NUKLIR, 1974, p. 217.

[2] A. . Raja, A. P. Srivastava, and M. Dwivedi, Power Plant Engineering. New Delhi: New Age International Publisher, 2006.

[3] J. J. Duderstadt and L. J. Hamilton, "Nuclear Reactor Analysis." McGraw-Hill, New York, p. 650, 1942.

[4] B. R. Hunt, R. L. Lipsman, J. M. Rosenberg, K. R. Coombes, J. E. Osborn, and G. J. Stuck, A Guide to Matlab. Cambridge: Cambridge University Press, 2001.

[5] S. C. Chapra and R. P. Canale, "Numerical Methods for Engineers for Engineers." McGraw-Hill, New York, p. 968, 2010.

[6] M. D. Isnaini, "ANALISIS DISAIN TERMOHIDROLIKA SUB KANAL ELEMEN BAKAR PWR-KSNP," in Prosiding PPI-PDIPTN Pusat Akselerator dan Proses Bahan, 2007, p. 9 .

[7] M. Khoiri, T. W. Tjiptono, and A. Prihastomo, "PEMBUATAN KODE KOMPUTER UNTUK ANALISIS AWAL TERMOHIDROLIK SUBKANAL PENDINGIN REAKTOR LWR," in SDM Teknologi Nuklir VII, 2011.

[8] N. E. Todreas and M. S. Kazimi,
Nuclear Systems I: Thermal Hydraulic Fundamentals. Vol. 1. New York: Taylor \& Francis, 1990.

[9] S. Pramuditya, "Pengembangan kode komputer terintegrasi untuk studi desain awal pembangkit listrik tenaga nuklir jenis pwr," Institut Teknologi Bandung, 2007.

[10] Suroso (BATAN) and S. Dibyo, "PEMODELAN

TERMOHIDROLIKA SUBKANAL ELEMEN BAKAR AP1000 MENGGUNAKAN RELAP5," Uraina, vol. 16, no. 4, pp. 194-205, 2010.

[11] A. Setiyo and M. Munir, "Analisis Distribusi Suhu Aksial Teras Dan Penentuan k eff PLTN Pebble Bed Modular Reactor ( PMBR ) 10 MWE Menggunakan Metode MCNP 5," vol. 12, no. 3, pp. 85-90, 2010.

[12] S. Dibyo, "Kajian Dalam Penentuan Faktor Friksi Aliran Pendingin," in Seminar Hasil Penelitian P2TRR, 2002, pp. 203-210.

[13] M. Skrzypek and R. Laskowski, "Thermal-hydraulic calculations for a fuel assembly in a European Pressurized Reactor using the RELAP5 code," Nukleonika, vol. 60, no. 3, pp. 537-544, 2015.

[14] S.H. Ahn and G.D. Jeun, "Effect of spacer grids on $\mathrm{CHF}$ at PWR operating conditions," J. Korean Nucl. Soc., vol. 33, no. 3, pp. 283297, 2001. 